\title{
EXPERIMENTAL INVESTIGATION OF BENDING FATIGUE, BREAKING LOAD AND CORROSION PERFORMANCE OF STEEL WIRE ROPES WITH INDEPENDENT WIRE ROPE CORE(IWRC) AND IMPREGNATED PLASTIC CORE(EPIWRC)
}

\author{
Murat POLAT ${ }^{1}$, Rıza KÖSELER ${ }^{1}$, İlbeyi KILAVUZ² \\ ${ }^{1}$ Çelik Halat ve Tel Sanayi A.Ş - Kartepe, Kocaeli, Turkey, mpolat@celikhalat.com.tr \\ ${ }^{2}$ Ford Otosan Ihsaniye Automotive Vocational School, Kocaeli University - Ihsaniye, Kocaeli, Turkey, \\ ilbeyi@kocaeli.edu.tr
}

https://doi.org/10.37904/metal.2021.4145

\begin{abstract}
Steel wire ropes are lifting equipments used in many areas such as fishing, mining, oil\&gas, construction and marine. Steel wire ropes, which stand out with their high lifting capacity and optimum elongation, can be produced in different properties and constructions. Steel wire ropes with impregnated plastic core are used in special cranes where high breaking load is required, in harbour cranes with corrosive effects and in the mining industry where there is pollution. These ropes are generally preferred with a diameter of 16-56 mm and can be produced as 6 stranded, 8 stranded and multiple stranded (i.e $34 \times 7,35 \times 7,40 \times 7$ etc.). Multiple stranded ropes are characterized as rotational resistant and are preferred in high-level applications. In this study; the bending fatigue, breaking load and corrosion performance of steel wire ropes with impregnated plastic core(EPIWRC) was investigated. The tensile tests, corrosion tests and bending fatigue tests of the rope with $8 \times 26$ WS construction used in the study were performed and the parameters affecting the fatigue life of the ropes were determined. As a result of the tensile tests, it was determined that the steel wire ropes with impregnated plastic core have $10 \%$ higher breaking load than the steel wire ropes with independent wire rope core. It has been observed that the plastic coating significantly protects the steel core of the rope from corrosion and friction and reduces wire breakage. It has been determined that the decrease in the number of wire breakages and the minimization of the friction contacts increase the fatigue life of the rope. This study includes experimental data on steel wire ropes.
\end{abstract}

Keywords: Steel wire rope, bending fatigue, friction and wear, corrosion

\section{INTRODUCTION}

Steel wire ropes are lifting equipment produced by using high carbon pearlitic steel wire rods. Steel wire ropes are used in many areas of industry and are preferred especially in elevator systems, fishing boats, harbor cranes, oil drilling lines and mining equipment [1].

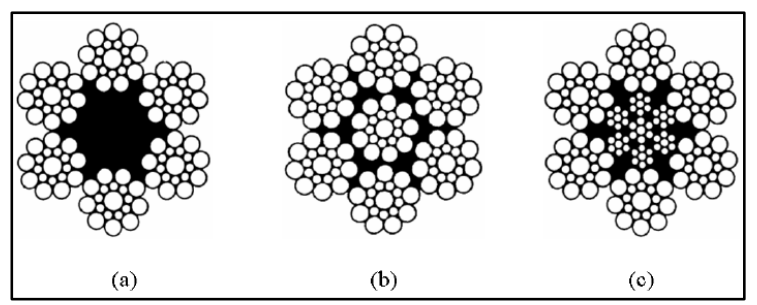

Figure 1 Core types of steel wire ropes; a) FC, b) WSC, c) IWRC [2]

Depending on the application of use, steel wire ropes can be produced as fiber core (FC), independent wire rope core (IWRC) and wire strand core (WSC). While fiber core ropes are preferred in areas where flexibility 
and extension capability are required, independent wire rope core and wire strand core ropes are preferred in applications requiring high breaking load. Core types used in steel wire ropes are given in Figure 1.

Steel wire ropes are produced in different strand constructions. Wire ropes have different strand constructions, these structures are named as standard, warrington, seale, filler, seale-filler and warrington-seale according to the production variable [3].

After the formation of rope constructions in historical development, sectoral demands have increased and special rope designs with high breaking load and service life have been studied. For high breaking load and service life in steel wire ropes, areas such as wire strength, rope construction, additional lubricant and structural protectors have been studied.

With the experience gained in the past in historical studies, a standard named "ISO 4309-Cranes-Wire ropesCare and maintenance, Inspection and discard" has been established to determine the service life of ropes. Historical experiences and this standard are used in scientific studies.

Suh and Chang [4] investigated the axial fatigue behavior of suspension ropes used in suspension bridges. Variable test parameters were determined as strain, strain range and sample length. According to the findings obtained as a result of the study; It has been determined that the wire fractures experienced occur as a result of fatigue at the wear points where the outer strands come into contact, the amount of stress significantly affects the fatigue life. It was revealed that the decrease in fatigue life as a result of the increase in the sample size was inconsistent with the previous studies and therefore the tests should be repeated. It has been found that the stress range reveals a significant life change and confirms that conventional $\mathrm{S}-\mathrm{N}$ curves can be used in the design.

Zhang and Qiang [5] experimentally investigated the effects of contact wear on bending fatigue life in steel wire ropes used in coal mines. In the experiment, tests were carried out using an elastic swing test device. In the results of working; It has been determined that the friction at the contact points decreases depending on the load and is fixed after a certain point, and the abrasion depth increases depending on the friction time and contact tension. It has been verified by SEM analysis that the notch formed in the friction areas progresses and causes fatigue fractures and directly affects the fatigue life.

Onur and İmrak [6] examined theoretically and experimentally the fatigue performance of steel wire rope with $10 \mathrm{~mm}$ diameter and 6x36WS construction on sheaves. Rope life was calculated by Feyrer's theoretical estimation method. As a result of the study, it was determined that as the breaking load increases and the pulley diameter decreases, the life of the rope decreases. The theoretical results calculated with the Feyrer Approach Method are consistent with the experimental results.

The aim of the study is to examine the effect of coating on rope strength, bending fatigue life and corrosion behavior in ropes with essence plastic filled. In the study, tensile, corrosion and bending fatigue tests will be applied to IWRC and EPIWRC steel wire ropes.

\section{EXPERIMENTAL DETAILS}

For the study, an independent wire rope core(IWRC) and impregnated plastic core(EPIWRC) ropes of 8x26WS construction with a diameter of $22 \mathrm{~mm}$, wire strength of $1960 \mathrm{MPa}$ was used. Detailed information about the samples is given in Table 1.

Table 1 Sample Information to be used in the study

\begin{tabular}{|c|c|c|c|c|c|c|}
\hline Sample No & $\begin{array}{c}\text { Diameter } \\
(\mathbf{m m})\end{array}$ & Construction & $\begin{array}{c}\text { Tensile Grade } \\
\mathbf{M P a}\end{array}$ & Core Type & Core Construction & Lay Ratio \\
\hline 1 & 22 & $8 \times 26$ WS & 1960 & IWRC & $7 \times 7$ & 6.50 \\
\hline 2 & 22 & $8 \times 26$ WS & 1960 & EPIWRC & $6 \times 175$ & 6.50 \\
\hline
\end{tabular}


2D and 3D designs were made in the Solidworks program for the visual verification and the control of the contact areas of the samples to be produced. 2D and 3D drawings of Sample 1 and Sample 2 are given in Figure 2.

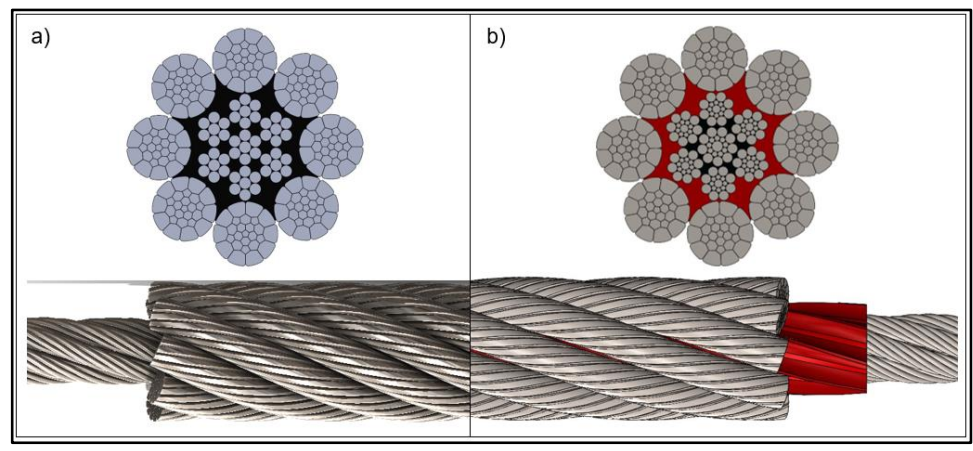

Figure 2. 2D and 3D designs; a)Sample 1(IWRC) b)Sample 2(EPIWRC)

For the tensile tests, 1.20 meters samples were taken from the produced steel wire ropes. Both ends of the samples are terminated with a zinc head. Tensile tests were carried out according to EN 12385-1.

Corrosion tests were carried out in a cyclic test cabinet according to ASTM B-117. For the tests, 0,50 meter samples were cut from steel wire ropes and placed in the test cabinet simultaneously. The test was continued until red rust formed in both samples. At the end of the test, the surfaces of the samples and the corrosion condition of the independent wire rope core(IWRC) and impregnated plastic core(EPIWRC) were examined.

Bending fatigue tests are performed on devices specially designed for steel wire ropes. Ropes mounted on the test device consisting of one drive sheave and one test sheave are subjected to cyclic motion. The test is completed when reference values such as diameter reduction and number of wire breaks in the ISO 4309 standard are reached. The bending fatigue test principle is given in Figure 3.

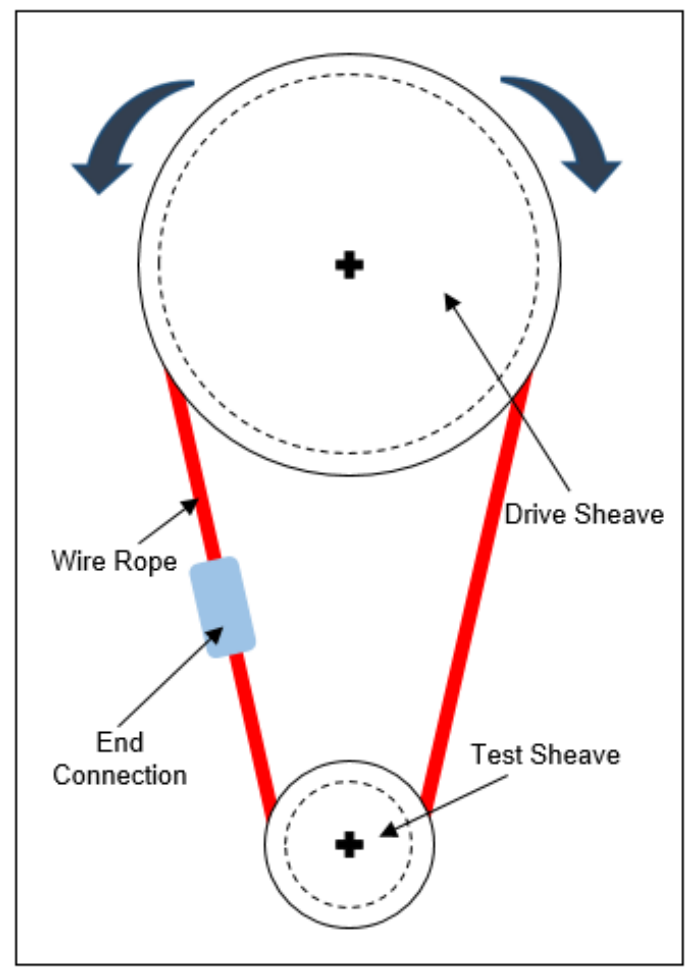

Figure 3 Test Principle of Bending Fatigue Test 


\section{RESULTS AND DISCUSSION}

Three tensile tests were carried out on independent wire rope core(IWRC) and impregnated plastic core(EPIWRC) steel wire ropes. Tensile test diagrams are given in Figure $\mathbf{4}$ and detailed test results are given in Table 2.
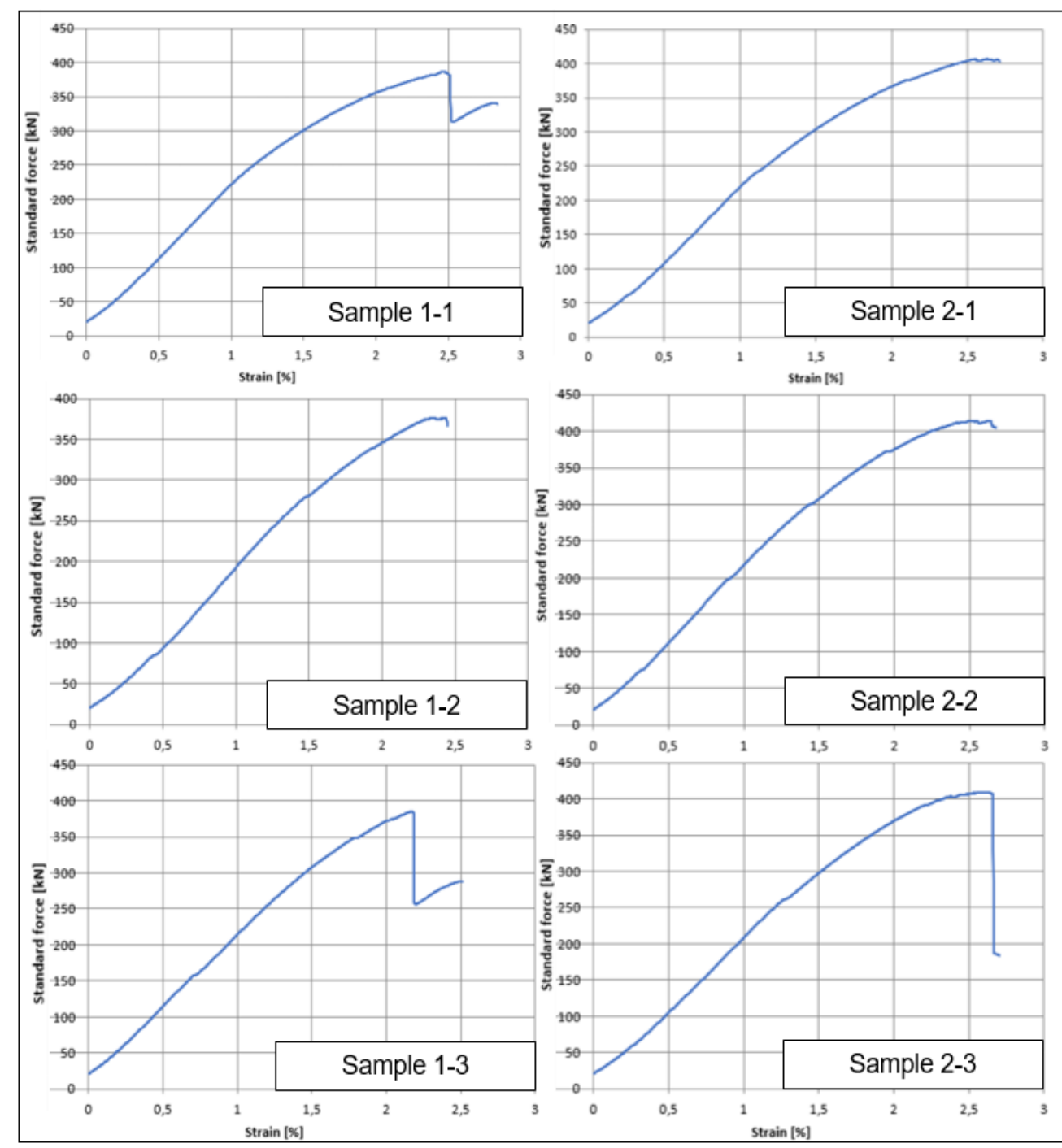

Figure 4 Tensile test diagrams of all samples

Table 2 Tensile test results of all samples

\begin{tabular}{|c|c|c|c|c|c|c|}
\hline Sample No & $\begin{array}{l}\text { Breaking } \\
\text { Load(Fm) } \\
\text { kN }\end{array}$ & $\begin{array}{c}\text { Elasticity } \\
\text { Modulus (E) } \\
\text { GPa }\end{array}$ & $\begin{array}{c}\text { Elongation } \\
\%\end{array}$ & $\begin{array}{c}\text { Average } \\
\text { Breaking } \\
\text { Load(Fm) } \\
\text { kN } \\
\end{array}$ & $\begin{array}{c}\text { Average } \\
\text { Elasticity } \\
\text { Modulus (E) } \\
\text { GPa }\end{array}$ & $\begin{array}{c}\text { Average } \\
\text { Elongation } \\
\%\end{array}$ \\
\hline Sample 1-1 & 382 & 100 & 2.5 & \multirow{3}{*}{380} & \multirow{3}{*}{97} & \multirow{3}{*}{2.3} \\
\hline Sample 1-2 & 375 & 99 & 2.4 & & & \\
\hline Sample 1-3 & 383 & 92 & 2.2 & & & \\
\hline Sample 2-1 & 409 & 103 & 2.7 & \multirow{3}{*}{415} & \multirow{3}{*}{104} & \multirow{3}{*}{2.7} \\
\hline Sample 2-2 & 419 & 107 & 2.6 & & & \\
\hline Sample 2-3 & 417 & 101 & 2.7 & & & \\
\hline
\end{tabular}


As a result of the tensile tests, it was determined that the average breaking load with independent wire rope core(IWRC) was $380 \mathrm{kN}$ and the average breaking load with impregnated plastic core(EPIWRC) was $416 \mathrm{kN}$. According to the results, it was determined that the ropes with plastic impregnated core(EPIWRC) had $10 \%$ higher breaking load. When the elasticity modulus and elongation results were examined, it was seen that the ropes showed similar properties.

Bending fatigue tests were performed on the samples. Test parameters and details of their results are given in Table 3. Test results were made in a theoretical and ideal setup. In physical applications, these values may not be reached due to load distribution, usage and equipment condition. According to the test results, ropes with impregnated plastic core(EPIWRC) theoretically have $40 \%$ of higher service life in tests.

Table 3 Bending fatigue test parameters and results

\begin{tabular}{|c|c|c|c|c|c|}
\hline Sample No & $\begin{array}{c}\text { Diameter } \\
(\mathbf{m m})\end{array}$ & Core Type & $\begin{array}{c}\text { Breaking Load(Fm) } \\
\mathbf{k N}\end{array}$ & Load Level & $\begin{array}{c}\text { Number of } \\
\text { Bending Cycles }\end{array}$ \\
\hline Sample 1 & 22 & IWRC & 382 & $20 \%$ (Safety Factor 5) & 38.868 \\
\hline Sample 2 & 22 & EPIWRC & 417 & $20 \%$ (Safety Factor 5) & 56.833 \\
\hline
\end{tabular}

The samples were tested for 1000 hours of corrosion. The samples placed in the corrosion cabinet in the area where equivalent effects occurred were tested for 1000 hours and controls were carried out every 24 hours. The times of white and red rust in the samples are given in Table 4.

Table 4 Corrosion Test Parameters and Results

\begin{tabular}{|c|c|c|c|c|c|}
\hline Sample No & $\begin{array}{c}\text { Diameter } \\
(\mathbf{m m})\end{array}$ & Core Type & $\begin{array}{c}\text { Test Period } \\
\mathbf{h}\end{array}$ & $\begin{array}{c}\text { White Rust } \\
\text { Period } \\
\mathbf{h}\end{array}$ & $\begin{array}{c}\text { Red Rust } \\
\text { Period } \\
\mathbf{h}\end{array}$ \\
\hline Sample 1 & 22 & IWRC & 1000 & 380 & 540 \\
\hline Sample 2 & 22 & EPIWRC & 1000 & 460 & 690 \\
\hline
\end{tabular}

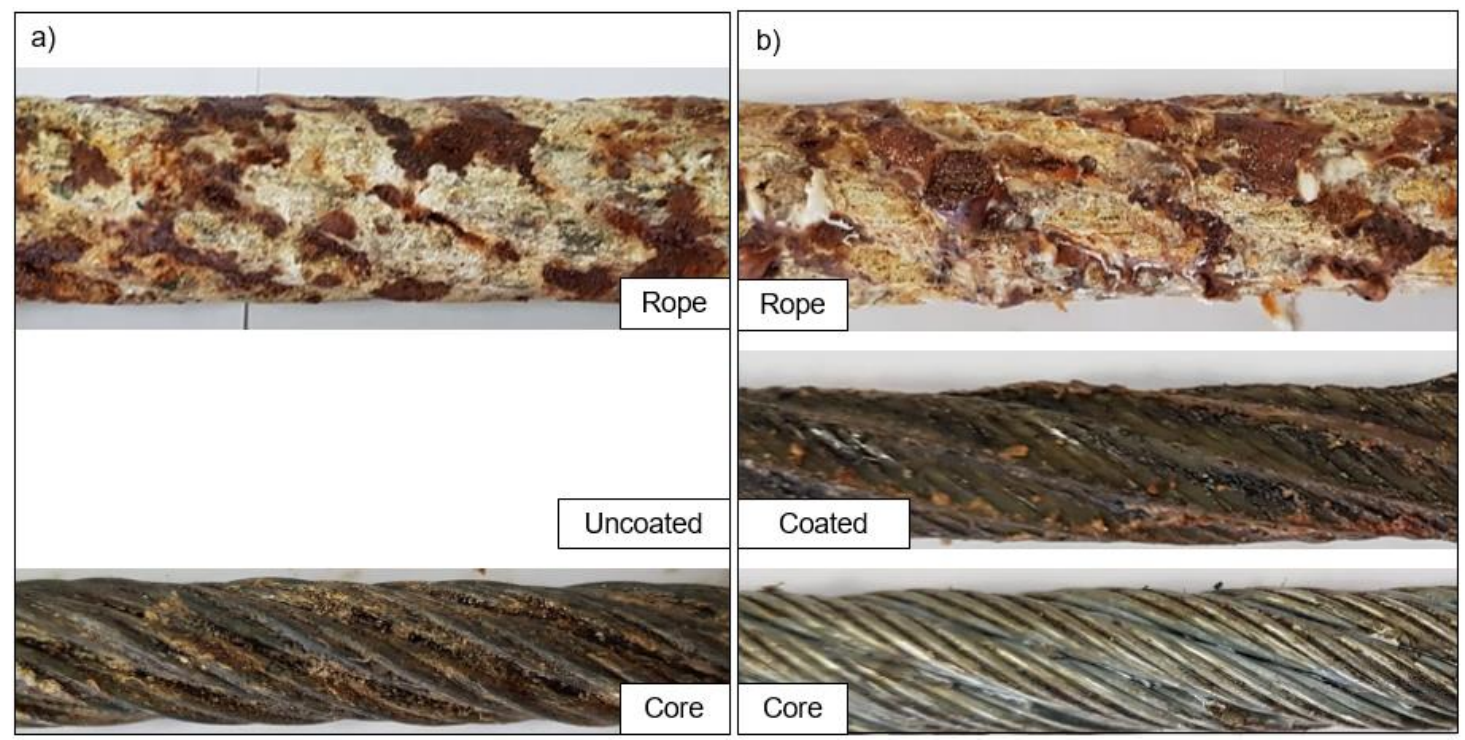

Figure 5 Visual conditions of steel wire rope samples and steel cores; a) Sample 1(IWRC), b) Sample 2(EPIWRC)

After 1000 hours, the outer strands of the samples taken out of the test cabinet were opened and the core conditions of the ropes were checked. Images of samples and steel cores are given in Figure $\mathbf{5}$. In the 
examination, it has been observed that internal corrosion is much higher in independent wire rope core(IWRC) ropes and the coating protects the visual conditions of ropes significantly in impregnated plastic core(EPIWRC) ropes. In addition, it has been determined that white and red rust formation occurs later in ropes with impregnated plastic core(EPIWRC) compared to independent wire rope core(IWRC).

\section{CONCLUSION}

Rope production is a complex process. With the development in the steel rope industry, it became possible to produce ropes with a longer life and higher strength. In the study, the breaking load, bending fatigue life and corrosion performances of independent wire rope core(IWRC) and impregnated plastic core(EPIWRC) ropes were investigated. As a result of the study, it was determined that impregnated plastic core(EPIWRC) ropes provide $10 \%$ of higher strength and $40 \%$ of higher fatigue resistance compared to independent wire rope core(IWRC) ropes. When the corrosion tests were examined, it was determined that white and red rust formation was seen later in impregnated plastic core(EPIWRC) ropes and the steel core was significantly protected from corrosion. Considering all the results, impregnated plastic core(EPIWRC) ropes can be preferred in critical applications where pollution and corrosive effects are intense and high breaking load and service life are required.

\section{ACKNOWLEDGEMENTS}

This study was funded The Scientific and Technological Research Council of Turkey (TUBITAK) project 3191466. Thanks to Çelik Halat ve Tel Sanayi A.Ş. for laboratory and test facilities in this project.

\section{REFERENCES}

[1] GÜZEY, A. Demirsel Tellerin Üretim Sürecinin Incelenmesi. Edirne: Yüksek Lisans Tezi. Trakya Üniversitesi, 2009.

[2] Anon. Steel Wire Ropes and Fittings. Bridon Ropes, 1992.

[3] USHA Martin. Wire Rope Handbook. [online]. 2012. [viewed in 2021-03-24]. Available from: http://www.ushamartin.com/wp-content/uploads/2014/04/Wire-Rope-Handbook.pdf

[4] SUH, J. CHANG, S. Experimental study on fatigue behaviour of wire ropes. International Journal of Fatigue. 2000. vol. 22, pp. 339-347.

[5] ZHANG, D. GE, S. QIANG, Y. Research on the fatigue and fracture behavior due to the fretting wear of steel wire in hoisting rope. Wear. 2003, vol. 255, pp. 1233-1237.

[6] ONUR, Y. IMRAK, C. Experimental and Theoretical investigation of bending over sheave fatigue life of stranded steel wire rope. Indian Journal of Engineering \& Material Sciences. 2012, vol. 19, pp. 189-195. 